\title{
Authoritarianism and exposure to another's behavior in a risk-taking situation
}

ROBERT A. BARON AND SIDNEY J. ARENSON UNIVERSITY OF IOWA

Six groups of Ss, based on combinations of two levels of $F$ scale scores and three levels of confederate risk-taking, took part in a game where they made decisions about accepting known outcomes or gambling on unknown alternatives. Results indicated that an individual's behavior is significantly influenced by another's responses in this situation. High $F$ and Low $F$ Ss did not differ in susceptibility to social influence or tendency to gamble under these conditions.

In a recent study (Raynor \& Smith, 1966) evidence was found for a relationship between scores on the California F scale (Adorno et al, 1950) and behavior in a risk-taking situation. In one experimental group, the higher an individual's $F$ scale score, the higher the mean probability of the bets he preferred. The correlation coefficient between scores on the $\mathrm{F}$ scale and a measure of the mean probability of bets Ss selected was +.52 . The present study was designed to explore this suggestion of a relationship between relative conservatism in a risk-taking situation and high scores on the F scale. Specifically, the following hypotheses were tested: (1) High F individuals are relatively conservative in risk-taking situations as compared with low $F$ individuals; (2) High F individuals are more susceptible to social influence in risk-taking situations than low F individuals; (3) Subject behavior is influenced by the responses of another person in a risk-taking situation.

\section{Method}

Two months before the start of the experimental sessions, 208 undergraduate males at the University of lowa completed a true-false form of the $F$ scale. Forty-five of the $50 \mathrm{Ss}$ scoring highest and 45 of the 50 Ss scoring lowest on this scale participated in the experiment. The mean $F$ scale scores for the High $F$ and Low $F$ groups were 16.29 and 5.19, respectively.

The apparatus consisted of an S.V.E. "Instructor $500 "$ manually operated slide projector, two $35 \mathrm{~mm}$ slides, two piles of "Unknown Alternative" cards, and "Betting Sheets." The slides contained a typed +1 and -1 . Each pile of Unknown Alternative cards consisted of $503 \times 5$ in. index cards, on each of which was typed one of the numbers from -2 to -6 , or +2 to +6 . Five cards of each value were used in each pile.

A completely randomized 2 by 3 factorial design employing 15 Ss in each of six conditions was used. The two experimental factors were $F$ scale score and confederate risk-taking level. Under high risktaking confederate condition (HRC), the confederate gambled on 96 percent of the trials (100 percent of the -1 and 92 percent of the +1 trials). Under low risk-taking confederate conditions (LRC), the confederate gambled on 30 percent of the trials (40 percent of the -1 and 20 percent of the +1 trials). In the no confederate conditions (NRC), Ss came to the experiment alone and were not exposed to the behavior of another person.

The task used was an adaptation of the procedures employed by Myers \& Sadler (1960). Ss were told that they would each see one random series of slides consisting of $-1 \mathrm{~s}$ and $+1 \mathrm{~s}$. Each time a slide was shown the player whose turn it was could choose to accept the outcome shown on the slide (i.e., win or lose one point), or take a chance on the pile of Unknown Alternative cards. If $S$ chose to accept the outcome shown on the slide, he was to say "Don't gamble." If he decided to take a chance on the Unknown Alternative cards, he was to say "Gamble." Each $S$ was to enter either the outcome shown on the slide (if he decided to accept this result) or a check mark (if he decided to gamble) in the appropriate space on the Betting Sheet. It was explained that when both Ss had completed their series of slides, they could go back and turn over one Unknown Alternative card for each check mark they had made. These cards would then determine the number of points they had won or lost. The stated object of the game was to win as many points as possible. The confederate responded first, after which $\mathrm{S}$ responded to the same series of slides. The same random order of slides was used for all Ss. In the NRC groups, Ss made their responses with only the $E$ present. These Ss were exposed to the series of slides twice, but responded only during the second presentation. Results

The dependent measures of risk-taking were the number of gambles on +1 and -1 trials. The mean number of gambles on +1 trials in each of five blocks of five occurrences of +1 in the random order of slides are presented for all groups in Fig. 1. For both HF and LF Ss, HRC groups made more gambles than LRC groups, in all blocks of trials. The effect of confederate risk-taking level was found to be significant in an analysis of variance $(F=8.33$, df $=2 / 89, p<.001$ ). Neither the effect of $F$ scale score nor the interaction of this factor with that of confederate risk-taking level was significant. To examine the specific effects of confederate behavior, comparisons were made between the means of the NRC, 


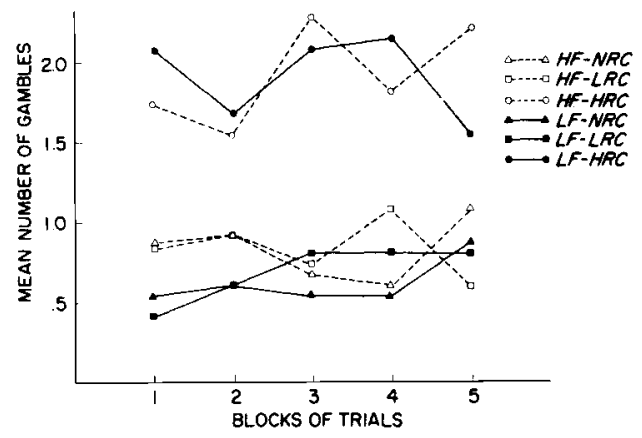

Fig. 1. Mean number of gambles in blocks of +1 trials.

LRC, and HRC groups, collapsed over F scale score level, by means of the critical difference technique (Lindquist, 1953, p. 92). The means for these groups were $3.89,3.76$, and 8.56 , respectively. The means of the HRC and NRC groups and those of the HRC and LRC groups differed significantly $(p<.05)$. The means of the LRC and NRC groups did not differ significantly. Thus, exposure to the behavior of a high-risk confederate had a significant effect upon the behavior of the Ss.

The results of analyses performed on the number of gambles on -1 trials were highly similar to those reported above for the number of gambles on +1 trials. Thus, they will not be described at this point. Discussion

The hypotheses that HF Ss would be more conservative and more susceptible to social influence than LF Ss in a risk-taking situation were not confirmed. However, the hypothesis that the behavior of the Ss would be influenced by the behavior of another person in a risk-taking situation was supported. This effect of another person's responses upon the behavior of the Ss was attributable to the high-risk confederate. A possible reason for this finding is that the high-risk confederate was closer to the maximum possible percentage of gambling than the low-risk confederate was to the minimum possible percentage of gambling.

The effect of another's responses upon subject behavior is especially interesting because Ss had no knowledge of their own or the other person's outcomes if they gambled. Thus, this result cannot be explained in terms of Ss' matching the behavior of a component model. Previous evidence (Bandura \& Huston, 1961; Bandura, Ross, \& Ross, 1963) has indicated that Ss will match the behavior of a model even when the outcomes of the model are unknown and $\mathrm{S}$ receives no overt reinforcement for such behavior.

Blake (1958) has reported several studies in which it was found that college students are more likely to perform certain responses (e.g., signing a petition) when they observe others performing these responses immediately before being requested to do so themselves. In these situations, neither the model nor $\mathrm{S}$ was reinforced overtly for performing the critical response. In discussing these results, Blake states (p. 241), "The perception of the reactions of the other person can function as the beginning of a norm which then becomes a standard way for the behavior of many others. Thus, the model for the development of social order is one person adjusting his behavior as a function of perceiving the actions of another person, when both are perceiving a common central stimulus."

In the present experiment both the $S$ and the confederate were exposed to the same stimuli, and, because the confederate always responded first, $S$ was able to observe his responses to these stimuli. Thus, it is possible that the confederate's responses provided a standard or norm for behavior in this situation. Further investigation is necessary to determine the risk conditions under which such "adjustment" of the behavior of one individual to that of another will, or will not, occur.

\section{References}

ADORNO, T. W., FRENKEL-BRUNSWICK, E., LEVINSON, D, J., \& SANFORD, R. N.The authoritarian personality, New York: Harper, 1950.

BANDURA, A., \& HUSTON, A. C. Identification as a process of incidental learning. J. abnorm. soc. PsychoL, 1961, 63, 311-318.

BANDURA, A., ROSS, S., \& ROSS, D. Transmission of aggression through imitation of aggressive models. J. abnorm. soc. Psychol, $1961,63,575-582$.

BLAKE, R. The other person in the situation. In Tagiuri, R., and Petrullo, L., (Eds.) Person perception and interpersonal behavior. Stanford: Stanford University Press, 1958.

LINDQUIST, E. F. Design and analysis of experiments. Boston: Houghton Mifflin Co., 1953.

MEYERS, J. L., \& SADLER, E. Effects of range of payoff as a variable in risk-taking. J. exp. Psychol., 1960, 60, 306-309.

RAYNOR, J., \& SMITH, C. P. Achievement-related motives and risktaking in games of skill and chance. J. Pers. 1966, 34, 176-198.

Note

1. Based on a master's thesis submitted to the Graduate College of the University of lowa by the first author under the direction of the second author. 